\title{
Food-choice motives of adolescents in Jakarta, Indonesia: the roles of gender and family income
}

\author{
Rizka Maulida ${ }^{1}$, Keiko Nanishi ${ }^{2, *}$, Joseph Green ${ }^{3}$, Akira Shibanuma $^{2}$ and \\ Masamine Jimba ${ }^{2}$ \\ ${ }^{1}$ Faculty of Public Health, Universitas Indonesia, Kampus UI Depok, Depok, Indonesia: ${ }^{2}$ Department of Community \\ and Global Health, Graduate School of Medicine, The University of Tokyo, 5th Floor, Medical Bldg No. 3, 7-3-1 \\ Hongo, Bunkyo-ku, Tokyo 1 13-0033, Japan: ${ }^{3}$ Department of International Epidemiology, Graduate School of \\ Medicine, The University of Tokyo, Tokyo, Japan
}

Submitted 15 November 2015: Final revision received 21 March 2016: Accepted 30 March 2016: First published online 16 May 2016

\begin{abstract}
Objective: The aims of the present study were to assess the reliability and validity of the Food Choice Questionnaire (FCQ) and to determine the factors associated with food-choice motives in public junior-high-school students in Jakarta, Indonesia.

Design: Cross-sectional study with self-administered questionnaires. Trained research assistants measured height and weight of the participants on the day of the data collection.

Settings: Fourteen randomly selected public junior-high schools in East Jakarta, Indonesia.

Subjects: Public junior-high-school students ( $n$ 681) in grades 7 and 8, aged 13-14 years (377 girls and 304 boys).

Results: Three food-choice motives (subscales) were obtained from factor analysis and reliability testing: (i) comfort; (ii) convenience and price; and (iii) health. The subscale with the greatest mean value was health. Family affluence was inversely associated with the convenience and price subscale $(\beta=-0.05, P=0.01)$ and with the health subscale $(\beta=-0.04 ; P=0 \cdot 02)$. Females were less likely than males to consider health when choosing foods $(\beta=-0 \cdot 16 ; P=0 \cdot 03)$.

Conclusions: While its factor structure differed from those found in previous studies of adults, the FCQ can provide reliable measures of food-choice motives among these adolescents. Students from less affluent families placed more importance on food's convenience and price, but more affluent students did not necessarily make healthier choices. Compared with females, males were more likely to choose healthy foods. Future interventions should be tailored based on the socio-economic status of the target group.
\end{abstract}

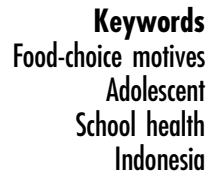

Although undernutrition remains a problem in low- and middle-income countries, obesity has also become a burden $^{(1)}$. Many people in these countries are taking on a modern, industrialized lifestyle, which is often associated with a lack of physical activity, adverse dietary changes and obesity, and this is occurring much faster than it did in European and other industrialized countries ${ }^{(2)}$. Lifestyle changes, including changes in eating habits, are often more evident among urban adolescents ${ }^{(3,4)}$. In some countries, urban children consume a majority of their energy from food that is prepared away from home ${ }^{(5)}$. In one study, as children matured through adolescence, fruit and vegetable consumption decreased by 41 and $25 \%$, respectively, whereas consumption of soft drinks increased by more than $200 \%^{(6)}$.
Among Indonesian children in urban areas the prevalences of overweight and obesity are increasing ${ }^{(7)}$. Additionally, according to the Indonesia Global School-Based Student Health Survey 2007, 5.8\% of junior-high-school students were at risk for becoming overweight and $1.3 \%$ were overweight ${ }^{(8)}$. In this context it is noteworthy that public schools in Indonesia do not have school lunch programmes.

Adolescents are prone to inappropriate eating habits, with several adverse consequences. For instance, adolescents who are overweight are more likely to suffer from diabetes as adults and as many as $25-50 \%$ of obese adolescents remain obese in adulthood ${ }^{(9-14)}$. Furthermore, eating a high-fat diet before adulthood is associated with heart disease ${ }^{(14,15)}$. 
Dietary behaviour during adolescence can establish habits that endure through adulthood ${ }^{(16)}$. In this period, the influence of the home environment diminishes and adolescents start to gain independence regarding what they eat ${ }^{(17)}$. They start to decide what, where and when they eat, and they eat more outside ${ }^{(18)}$.

Several studies of adolescents' motivation when choosing food have used primarily qualitative methods ${ }^{(17,19-22)}$. For quantitative research, one appropriate tool is Steptoe's Food Choice Questionnaire (FCQ). Results from use of the FCQ originally identified nine factors for food-choice motives. However, the number of motives found has varied across studies. Several adjustments have been made to the scale to expand the factors or to accommodate a number of factors for a specific population other than the UK population among whom it was used originally ${ }^{(23-25)}$.

In previous studies using the FCQ, gender and age were found to be associated with food-choice motives ${ }^{(24,25)}$. In adolescents, food-choice motives might also be associated with other factors, which could include BMI, parents' education, household socio-economic status and family dinner frequency, although they have not yet been studied $^{(26-33)}$. Those factors are known to be associated with dietary behaviour but their associations with food-choice motives are not known ${ }^{(26-33)}$. That gap in knowledge should be filled because 'effective modification of dietary patterns depends on an understanding of the factors governing food choice, ${ }^{,(34)}$.

To help adolescents make healthy choices, interventions should be based on evidence of their motives in choosing foods. Food-choice motives are associated with food intake, and choices of foods and beverages can affect the risk of overweight and obesity ${ }^{(35)}$. Therefore, interventions based on empirical evidence are needed to help prevent adolescents from making unhealthy choices. Steptoe's modified FCQ can be used to inform those interventions, but it has never been adapted and used properly in Indonesia. Therefore, we carried out reliability testing and validation testing of the FCQ among adolescents in Indonesia. To identify promising areas for interventions, we also studied factors that might influence food-choice motives.

\section{Methods}

This was a cross-sectional study conducted in East Jakarta Municipality, Jakarta Special Capital Region, Indonesia. The participants were public junior-high-school students in grades 7 and 8. Grade 9 students were not included because they were in their last year of junior-high school and were busy preparing for a national exam. Students who were excluded were those whose parents or guardians did not give consent, those with mental disability and those who could not communicate well in the local language (Bahasa Indonesia).

\section{Sample}

Sample size was calculated using the sampsi command in the statistical software package STATA 12.1. The calculation was done with power $=90 \%$ and $\alpha=5 \%$. The mean and SD were obtained from a previous study, in which the mean value of food-choice motive (health) for male adolescents was 2.54 with $\mathrm{SD}=0.55$ and the mean for female adolescents was 2.68 with $\mathrm{SD}=0.50^{(24)}$. The result of the calculation was 594 . Because the sample was derived from multiple schools, the design effect had to be taken into consideration; thus, further sample calculation was needed. In the next calculation, the intra-class correlation coefficient was assumed to be 0.005: $n=594 \times\{1+[(14-1) \times 0 \cdot 005]\}=632 \cdot 61$. The result was rounded to 633 . To account for dropouts, $10 \%$ was added to the total. The final result of the sample size calculation was 697.

A multistage sampling procedure was used. Each of the ninety-five schools in East Jakarta Municipality was placed into one of three groups based on the school's achievement on the national exam. Schools with the highest scores were placed in group A, those with somewhat lower scores were placed in group B, and those with the lowest scores were placed in group C. The two borders defining the three groups were the 33rd and 66th percentiles of the scores. From each group, five schools were randomly chosen. Lists of grade 7 and grade 8 students were provided by the schools, and from those lists forty students from each grade were randomly chosen. Several days before data collection, information sheets and informed consent forms were given to the parents of the chosen students. With the help of the school staff, the signed informed consent forms were collected from the students. Those students whose parents did not give consent were excluded from the study. Students who forgot to bring the form to school were included at the time, but if they failed to give the signed form to the research team at a later time, their data were excluded. One school agreed to participate at first but later withdrew from the study. Thus 1120 students were approached. Among them, 712 students were successfully recruited. Due to missing answers on the questionnaire data from thirty-one students were excluded, which resulted in a final sample of 681 (61\%).

\section{Measurements}

To measure food-choice motives, Steptoe et al.'s FCQ as modified by Lindeman and Väänänen was used. That modified version has eleven subscales: (i) health; (ii) mood; (iii) convenience; (iv) sensory appeal; (v) natural content; (vi) price; (vii) weight control; (viii) familiarity; (ix) ecological welfare; (x) political values; and (xi) religion. Each item in each subscale assesses the degree to which the respondent places importance on a certain motive when making food-related decisions, by using a 4-point Likert-type scale in which the 
responses are 'not at all important' (1), 'a little important' (2), 'moderately important' (3) and 'very important' (4). In previous studies, the internal consistency of the factors on the original scale ranged from 0.72 to 0.89 and the correlations between scores at two administrations of each FCQ scale were $>0 \cdot 70^{(23,34)}$.

The sociodemographic variables measured were gender, parents' education, parents' occupation and household socio-economic status. The response choices for parents' education were 'no diploma', 'graduated elementary school', 'graduated junior-high school', 'graduated senior-high school' and 'graduated university or college'. The response choices for parents' occupation were 'unemployed', 'civil servant', 'military or police', 'private sector', 'entrepreneur', 'labourer' and 'other'.

To measure household socio-economic status, the five-item Family Affluence Scale III (FAS III) was used. Items in the scale consisted of five easily answered and non-sensitive questions: (i) family-car ownership; (ii) the child having her or his own bedroom; (iii) the number of family vacations; (iv) the number of family computers; and (v) perception of family wealth. Coefficient $\alpha$ (internal consistency reliability) for the FAS III ranged from 0.32 to 0.62 across several studies ${ }^{(36)}$. The total score for family affluence is obtained by summing all the scores on FAS III. Higher scores indicate a higher socio-economic status. The highest score possible is 13 and the lowest is 1 . The FAS III had not been tested previously in Indonesia so the scale's face validity and reliability were also assessed, as described below.

BMI was calculated by dividing the participant's weight in kilograms by the square of the participant's height in metres. Measurements of the participants' weight and height were obtained on the day of data collection. The present study used the WHO categorization of BMI-for-age among 5-19-year-old-children for the descriptive analysis. The categories are 'severely thin', 'thin', 'normal', 'overweight' and 'obese'.

The participants were asked to indicate the number of times each week that their family had dinner together. The response choices were $0,1,2,3,4,5,6$ and 7 .

Nutritional knowledge was measured by using Section $\mathrm{H}$ of Turconi et al.'s dietary questionnaire ${ }^{(37)}$. Section $\mathrm{H}$ is the nutritional knowledge subscale; it consists of eleven items. In a previous study coefficient $\alpha$ was 0.56 and Pearson's correlation coefficient for each of the eight sections computed between the two administrations' total scores was $0 \cdot 80^{(37)}$. The entire scale, including Section $\mathrm{H}$, has not been tested in Indonesia, so its validity and reliability were assessed. In the current study coefficient $\alpha$ of the scale was 0.34 , which is much lower than the recommended minimum $\alpha$ of $0.7^{(38)}$. Factor analysis was done with tetrachoric correlations. Only the first factor had an eigenvalue greater than 1, and only two items had loadings greater than 0.5 on that factor: 'Which food is rich in protein?' (0.78) and 'Which substance has more energy?' (0.60). Therefore, for further analysis, only those two items were summed and used as an independent variable named 'knowledge about nutrition'. This variable was kept as a confounder in the multivariate analysis.

All of the items included on the questionnaire were translated from English to Bahasa Indonesia and then back-translated. The back translation was done by one of the research assistants. The translated questionnaire was also checked by a local expert.

\section{Results}

\section{Participants' characteristics}

Table 1 summarizes the participants' characteristics. The sample had nearly equal proportions of male students ( $n$ 304; 44.6\%) and female students ( $n$ 377; 55.4\%). Of the 681 participants, $1.2 \%$ were severely thin, $7 \cdot 8 \%$

Table 1 Participant characteristics: public junior-high-school students ( $n$ 681) in grades 7 and 8 (aged 13-14 years), East Jakarta, Indonesia, October 2014

\begin{tabular}{|c|c|c|}
\hline & $n$ or Mean & $\%$ or SD \\
\hline \multicolumn{3}{|l|}{ Gender } \\
\hline Male & 304 & $44 \cdot 6$ \\
\hline Female & 377 & 55.4 \\
\hline \multicolumn{3}{|l|}{ Mother's educational level } \\
\hline No diploma & 11 & $1 \cdot 6$ \\
\hline Graduated elementary school & 64 & 9.4 \\
\hline Graduated junior-high school & 85 & $12 \cdot 5$ \\
\hline Graduated senior-high school & 340 & $49 \cdot 9$ \\
\hline Graduated college/university & 181 & $26 \cdot 6$ \\
\hline \multicolumn{3}{|l|}{ Father's educational level } \\
\hline No diploma & 13 & 1.9 \\
\hline Graduated elementary school & 35 & $5 \cdot 1$ \\
\hline Graduated junior-high school & 71 & $10 \cdot 4$ \\
\hline Graduated senior-high school & 352 & 51.7 \\
\hline Graduated college/university & 210 & $30 \cdot 8$ \\
\hline \multicolumn{3}{|l|}{ Mother's occupation } \\
\hline Unemployed & 488 & 71.7 \\
\hline Civil servant & 47 & 6.9 \\
\hline Military/police & 7 & 1.0 \\
\hline Private sector & 62 & $9 \cdot 1$ \\
\hline Entrepreneur & 41 & $6 \cdot 0$ \\
\hline Labourer & 10 & 1.5 \\
\hline Other & 26 & 3.8 \\
\hline \multicolumn{3}{|l|}{ Father's occupation } \\
\hline Unemployed & 20 & 2.9 \\
\hline Civil servant & 76 & $11 \cdot 2$ \\
\hline Military/police & 42 & $6 \cdot 2$ \\
\hline Private sector & 180 & $26 \cdot 4$ \\
\hline Entrepreneur & 216 & 31.7 \\
\hline Labourer & 80 & $11 \cdot 8$ \\
\hline Other & 67 & 9.8 \\
\hline \multicolumn{3}{|l|}{$\mathrm{BMI}$} \\
\hline Severely thin & 8 & 1.2 \\
\hline Thin & 53 & $7 \cdot 8$ \\
\hline Normal & 447 & 65.7 \\
\hline Overweight & 111 & $16 \cdot 3$ \\
\hline Obesity & 62 & $9 \cdot 1$ \\
\hline Family affluence score, mean and SD & $6 \cdot 8$ & 2.6 \\
\hline $\begin{array}{l}\text { Frequency of family dinners per } \\
\text { week, mean and SD }\end{array}$ & 3.6 & $2 \cdot 4$ \\
\hline
\end{tabular}


were thin, $65.7 \%$ were in the normal range, $16.3 \%$ were overweight and $9.1 \%$ were obese.

For the FAS III, coefficient $\alpha=0 \cdot 64$. Compared with previous studies, the reliability of the scale in the present study was the highest ${ }^{(36,39)}$. Face validity of the FAS III was considered to be good, as the local experts (lecturers and other teaching staff of the Department of Nutrition, Faculty of Public Health, University of Indonesia) did not recommend that any items be added or removed. On the FAS III, the mean score was $6 \cdot 8$ with $\mathrm{sD}=2 \cdot 6$, the highest score was 13 and the lowest was 1 .

\section{Validity and reliability of the Food Choice Questionnaire}

The results from the Kaiser-Meyer-Olkin measure of sampling adequacy and Bartlett's test of sphericity indicated that the data were appropriate for factor analysis. The Kaiser-Meyer-Olkin measure of sampling adequacy value was 0.88 , which exceeded the recommended value of 0.6. Bartlett's test of sphericity confirmed a relationship between the variables with $P<0 \cdot 001$.

Principal factor analysis of the data from the thirty-three items resulted in eight factors with eigenvalues exceeding 1 , which accounted for $21 \cdot 7,8 \cdot 3,5 \cdot 2,4 \cdot 3,4 \cdot 0,3 \cdot 6,3 \cdot 4$ and $3 \cdot 2 \%$ of the variance, respectively. In Horn's parallel analysis, the eigenvalues of the first five factors from the actual data exceeded those of the first five factors from randomly generated matrices of the same size $(33$ variables $\times 681$ respondents). Oblique oblimin rotation was then conducted to aid the interpretation of the five factors using 0.5 as the cut-off point. This specific rotation was used because there was a correlation of 0.45 between factor 1 and factor 2 . After the rotation, twenty-one of thirty-three items had factor loadings above 0.5 (Table 2).

Those twenty-one items were then placed into five different subscales based on the loadings. Factor 1, here called 'comfort', contained five items that consisted of three 'mood' and two 'sensory appeal' items from the original FCQ. Factor 2, here called 'convenience and price', contained six items that consisted of three 'price' items, two 'convenience' items and one 'familiarity' item from the original FCQ. Factor 3, here called 'health', consisted of five 'health' items from the original FCQ. Factor 4, here called 'lifestyle', consisted of two 'weight control' items and one 'natural content' item from the original FCQ. Finally, factor 5, here called 'religion', consisted of two 'religion' items from Lindeman and Väänänen's revised FCQ. A reliability test was then performed on each subscale. The $\alpha$ coefficients of factors 1 to 5 were $0.79,0.76,0.72,0.45$ and 0.51 , respectively. Factors 4 and 5 were removed due to their low reliability, which left the final scale with three motives: 'comfort', 'convenience and price' and 'health'.

\section{Distribution of food-choice motives}

The mean scores and SD for each food-choice motive are shown in Table 3. The participants' most important motive when choosing foods was 'health' (mean score $=3.78$; $\mathrm{SD}=0.31$ ), followed by 'comfort' (mean score $=2 \cdot 92 ; \mathrm{SD}=0.61$ ) and 'convenience and price' (mean score $=2 \cdot 30 ; \mathrm{SD}=0.45$ ).

Table 2 Principal factor analysis of food-choice motives among public junior-high-school students $(n$ 681) in grades 7 and 8 (aged 13-14 years), East Jakarta, Indonesia, October 2014

\begin{tabular}{|c|c|c|c|c|c|}
\hline \multirow[b]{2}{*}{ Item } & \multicolumn{5}{|c|}{ Factor loadings } \\
\hline & 1 & 2 & 3 & 4 & 5 \\
\hline \multicolumn{6}{|l|}{ It is important to me that the food I eat on a typical day... } \\
\hline ...helps me relax & 0.75 & 0.00 & -0.01 & -0.01 & 0.10 \\
\hline ...helps me cope with stress & 0.73 & $-0 \cdot 10$ & 0.03 & $0 \cdot 12$ & 0.09 \\
\hline ...smells nice & 0.71 & 0.08 & -0.04 & -0.06 & $-0 \cdot 10$ \\
\hline ...cheers me up & 0.70 & 0.11 & 0.06 & 0.04 & -0.18 \\
\hline ...looks nice & 0.51 & 0.29 & $-0 \cdot 17$ & -0.07 & 0.13 \\
\hline ...can be bought in shops close to school or my house & -0.05 & 0.69 & 0.05 & -0.08 & 0.12 \\
\hline .... is easily available in shops and supermarkets & 0.13 & 0.63 & -0.03 & -0.03 & 0.13 \\
\hline ....is good value for money & $0 \cdot 17$ & 0.62 & -0.02 & 0.04 & -0.08 \\
\hline ....is what I usually eat & -0.02 & 0.59 & 0.21 & -0.12 & 0.04 \\
\hline ....is cheap & 0.07 & 0.57 & $-0 \cdot 11$ & $0 \cdot 13$ & -0.10 \\
\hline ....is not expensive & -0.05 & 0.56 & $-0 \cdot 15$ & 0.30 & -0.04 \\
\hline ...contains a lot of vitamins and minerals & -0.03 & -0.01 & 0.76 & 0.04 & 0.01 \\
\hline ... is high in protein & -0.06 & 0.03 & 0.71 & -0.03 & 0.14 \\
\hline ...keeps me healthy & 0.07 & -0.06 & 0.62 & 0.06 & 0.03 \\
\hline ...is nutritious & -0.07 & 0.02 & 0.58 & 0.09 & -0.14 \\
\hline ....is good for my skin/teeth/hair/nails, etc. & 0.19 & 0.05 & 0.55 & -0.04 & 0.07 \\
\hline ...is low in fat & -0.01 & 0.12 & $0 \cdot 10$ & 0.62 & 0.01 \\
\hline .... is low in calories & 0.06 & -0.04 & -0.00 & 0.60 & -0.03 \\
\hline ...contains no artificial ingredients & -0.05 & 0.06 & -0.04 & 0.55 & 0.21 \\
\hline ...is not forbidden by my religion* & -0.04 & 0.00 & -0.03 & 0.08 & 0.73 \\
\hline ... is in harmony with my religious views* & 0.04 & 0.08 & 0.14 & -0.03 & 0.72 \\
\hline
\end{tabular}

Bold font indicates which items loaded on the factor loadings in the respective columns.

${ }^{*}$ From Lindeman and Väänänen ${ }^{(23)}$. 


\section{Factors associated with food-choice motives}

Tables 4, 5 and 6 present the results of mixed-effect linear regression analyses between the three food-choice motives and all of the independent variables. Table 4 shows the results of multivariate analysis with the first motive ('comfort') as the dependent variable. This model did not show a significant association.

Table 5 shows the results of multivariate analysis with the second motive ('convenience and price') as the dependent variable. Family affluence was negatively associated with 'convenience and price' $(\beta=-0 \cdot 05, P=0 \cdot 010)$. Students from more affluent families were less likely to place value on convenience and price when choosing food.

Table 6 shows the results of multivariate analysis with the third motive ('health') as the dependent variable. Male students placed more importance on 'health' than did female students $(\beta=-0 \cdot 16 ; P=0 \cdot 029)$. Family affluence was negatively associated with 'health', which means that students from more affluent families were less likely to value health when choosing food $(\beta=-0 \cdot 04 ; P=0 \cdot 019)$.

\section{Discussion}

The results of the present study can be summarized into two main points. First, the factor structure of the FCQ in

Table 3 Distribution of food-choice motives among public juniorhigh-school students ( $n 681$ ) in grades 7 and 8 (aged $13-14$ years), East Jakarta, Indonesia, October 2014

\begin{tabular}{lccc}
\hline Food-choice motive & Number of items & Mean & SD \\
\hline Comfort & 5 & 2.92 & 0.61 \\
Convenience and price & 7 & 2.30 & 0.45 \\
Health & 5 & 3.78 & 0.31 \\
\hline
\end{tabular}

these adolescents differed from the structure reported previously in adults. Three motives were obtained from factor analysis and reliability testing of the FCQ in these adolescents: 'comfort', 'convenience and price' and 'health'. As judged from the means of the three subscales, 'health' was the dominant motive (i.e. it had the highest mean score). Second, food-choice motives were associated with family affluence and gender. The food-choice motive 'convenience and price' was more important for adolescents from less affluent families, and the food-choice motive 'health' was negatively associated with family affluence. Compared with female students, male students were more likely to consider health important.

Compared with previous studies in adults, the number of motives obtained in the present study is relatively small $^{(23,25,34)}$. There were only three motives with reliable subscales. However, the number of motives found in the current study differed little from that found in a previous study among adolescents ${ }^{(24)}$.

Another difference with previous studies is the factor structure of the motives. In the present study, three 'mood' items and two 'sensory appeal' items from the original FCQ loaded on a single motive: 'comfort'. The two 'sensory appeal' items were 'smells nice' and 'looks nice'. Two other 'sensory appeal' items ('tastes good' and 'has pleasant texture') did not load on any of the motives, which is similar to the results of Share and Stewart-Knox ${ }^{(24)}$. The reason for this difference between results from adolescents and results from adults is an important topic for further investigation ${ }^{(17,20,40)}$. In addition, olfactory senses are tied to emotions, which could explain why 'smells nice' loaded on the same factor as the mood items ${ }^{(41,42)}$. Much of what people commonly think of as a food's taste actually originates from the nose ${ }^{(43,44)}$.

Table 4 Factors associated with the food-choice motive 'comfort' among public junior-high-school students $(n$ 681) in grades 7 and 8 (aged 13-14 years), East Jakarta, Indonesia, October 2014

\begin{tabular}{lccc}
\hline & Coefficient $\beta$ & $P$ value & $95 \% \mathrm{Cl}$ \\
\hline Gender & 0.04 & 0.583 & $-0.11,0.19$ \\
Mother's educational level & & & -0.578 \\
$\quad$ Elementary school & 0.19 & 0.579 & $-0.48,0.87$ \\
Junior-high school & 0.20 & 0.570 & $-0.50,0.90$ \\
Senior-high school & 0.20 & 0.714 & $-0.48,0.88$ \\
University/college & -0.13 & & $-0.84,0.58$ \\
Father's educational level & & 0.635 & $-0.50,0.82$ \\
Elementary school & 0.16 & 0.937 & $-0.68,0.63$ \\
Junior-high school & -0.03 & 0.587 & $-0.80,0.45$ \\
Senior-high school & -0.17 & $-0.67,0.64$ \\
University/college & -0.02 & 0.964 & $-0.14,0.24$ \\
Mother's occupation (working/not working) & 0.05 & & $-0.36,0.60$ \\
Father's occupation & & 0.626 & $-0.37,0.58$ \\
Government/military & 0.12 & $-0.33,0.61$ \\
Private sector & 0.10 & $-0.37,0.59$ \\
Entrepreneur & 0.14 & 0.671 & $-0.02,0.05$ \\
Other & 0.11 & 0.643 & $-0.02,0.05$ \\
Family affluence & 0.02 & 0.348 & $-0.06,0.04$ \\
Family dinner frequency & 0.02 & 0.340 & $-0.19,0.11$ \\
BMl & -0.01 & 0.709 & 0.599 \\
Knowledge about nutrition & -0.04 & & \\
\hline
\end{tabular}


Table 5 Factors associated with the food-choice motive 'convenience and price' among public junior-high-school students ( $n$ 681) in grades 7 and 8 (aged 13-14 years), East Jakarta, Indonesia, October 2014

\begin{tabular}{|c|c|c|c|}
\hline & Coefficient $\beta$ & $P$ value & $95 \% \mathrm{Cl}$ \\
\hline Gender & -0.12 & 0.117 & $-0.27,0.03$ \\
\hline \multicolumn{4}{|l|}{ Mother's educational level } \\
\hline Elementary school & 0.42 & 0.223 & $-0.25,1.08$ \\
\hline Junior-high school & 0.63 & 0.076 & $-0.07,1.32$ \\
\hline Senior-high school & 0.59 & 0.085 & $-0.08,1.26$ \\
\hline University/college & 0.49 & 0.168 & $-0.21,1 \cdot 19$ \\
\hline \multicolumn{4}{|l|}{ Father's educational level } \\
\hline Elementary school & -0.24 & 0.469 & $-0.89,0.41$ \\
\hline Junior-high school & -0.06 & 0.866 & $-0.70,0.59$ \\
\hline Senior-high school & -0.37 & 0.242 & $-0.99,0.25$ \\
\hline University/college & -0.17 & 0.605 & $-0.82,0.48$ \\
\hline Mother's occupation (working/not working) & -0.02 & 0.858 & $-0.20,0.17$ \\
\hline \multicolumn{4}{|l|}{ Father's occupation } \\
\hline Government/military & -0.21 & 0.388 & $-0.69,0.27$ \\
\hline Private sector & -0.24 & 0.309 & $-0.71,0.23$ \\
\hline Entrepreneur & -0.12 & 0.625 & $-0.58,0.35$ \\
\hline Other & 0.01 & 0.951 & $-0.46,0.49$ \\
\hline Family affluence & -0.05 & 0.010 & $-0.08,-0.01$ \\
\hline Family dinner frequency & -0.01 & 0.613 & $-0.04,0.02$ \\
\hline BMI & 0.03 & 0.303 & $-0.03,0.08$ \\
\hline Knowledge about nutrition & 0.07 & 0.368 & $-0.08,0.21$ \\
\hline
\end{tabular}

Significant results are indicated in bold font.

Table 6 Factors associated with the food-choice motive 'health' among public junior-high-school students $(n 681)$ in grades 7 and 8 (aged 13-14 years), East Jakarta, Indonesia, October 2014

\begin{tabular}{|c|c|c|c|}
\hline & Coefficient $\beta$ & $P$ value & $95 \% \mathrm{Cl}$ \\
\hline Gender & -0.16 & 0.029 & $-0.31,-0.02$ \\
\hline \multicolumn{4}{|l|}{ Mother's educational level } \\
\hline Elementary school & 0.31 & 0.358 & $-0.35,0.97$ \\
\hline Junior-high school & 0.59 & 0.089 & $-0.09,1.28$ \\
\hline Senior-high school & 0.46 & 0.172 & $-0.20,1.12$ \\
\hline University/college & 0.44 & 0.213 & $-0.25,1.13$ \\
\hline \multicolumn{4}{|l|}{ Father's educational level } \\
\hline Elementary school & -0.20 & 0.539 & $-0.84,0.44$ \\
\hline Junior-high school & -0.46 & $0 \cdot 155$ & $-1.09,0.17$ \\
\hline Senior-high school & -0.32 & 0.302 & $-0.93,0.29$ \\
\hline University/college & -0.60 & 0.065 & $-1.24,0.04$ \\
\hline Mother's occupation (working/not working) & -0.04 & 0.678 & $-0.22,0.14$ \\
\hline \multicolumn{4}{|l|}{ Father's occupation } \\
\hline Government/military & 0.31 & $0 \cdot 196$ & $-0.16,0.78$ \\
\hline Private sector & 0.16 & 0.488 & $-0.30,0.63$ \\
\hline Entrepreneur & 0.33 & $0 \cdot 152$ & $-0.12,0.79$ \\
\hline Other & 0.41 & 0.085 & $-0.06,0.88$ \\
\hline Family affluence & -0.04 & 0.019 & $-0.08,-0.01$ \\
\hline Family dinner frequency & 0.03 & 0.057 & $0.00,0.06$ \\
\hline BMI & 0.05 & 0.073 & $0.00,0.10$ \\
\hline Knowledge about nutrition & -0.02 & 0.790 & $-0.17,0.13$ \\
\hline
\end{tabular}

Significant results are indicated in bold font.

Assessments of odours are affected by visual cues ${ }^{(45-47)}$ and colour affects children's food preferences ${ }^{(48)}$. This suggests that the olfactory and visual senses work together to arouse appetite.

In the present results, the items 'convenience', 'price' and 'familiarity' belonged to the food-choice motive 'convenience and price'. This is similar to Share and Stewart-Knox's finding that price and convenience are closely aligned motivators when adolescents choose foods ${ }^{(24)}$. However, unlike in the Share study, in the current study one 'familiarity' item also loaded with the 'convenience' and 'price' items. Collectively, these two studies suggest that adolescents are thinking of convenience and price in the same context.

In the present study family affluence and gender were associated with food-choice motives. Family affluence was negatively associated with the food-choice motive 'convenience and price'. Students from more affluent families put less importance on choosing food based on the food's convenience and price, whereas students from 
less affluent families considered the food's convenience and price to be more important than its other characteristics. This suggests that the latter students choose less expensive and more convenient meals rather than healthier foods. Food price has been shown to be an important determinant of food choice in several previous studies $^{(49-53)}$. Some studies conducted in France, Spain and the UK have suggested that diets containing the least healthy foods tend to cost less than diets containing healthier foods ${ }^{(54-56)}$. Moreover, a systematic review and meta-analysis found that healthier foods cost more than unhealthy foods ${ }^{(57)}$. Therefore, for adolescents in low socio-economic groups, price could be a barrier to healthier eating, which indicates an area for potential intervention.

Family affluence was also negatively associated with the food-choice motive 'health'. Students from more affluent families seemed to view health as less important than students from less affluent families. This finding is consistent with previous studies that showed a positive association between socio-economic status and BMI in developing countries ${ }^{(58-60)}$. In those countries, unhealthy meals and beverages are seen as luxury items; thus, people with higher incomes are more likely to choose them over healthier foods or drinks. A European study also found a similar situation: soft drink consumption in Central and Eastern European countries was positively associated with wealth ${ }^{(61)}$. This situation can be contrasted with that in other areas of Europe in which people do not view soft drinks as luxury items ${ }^{(61)}$.

Gender was also associated with the food-choice motive 'health'. In particular, health was more important to male students than to female students when choosing food. This is opposite to the results of other studies ${ }^{(23,24,34,62,63)}$. However, it is important to note that the 'weight control' motive was included in those five previous studies but it was not included in the final results of the current study (because of the factor-loading pattern and the low reliability of that subscale). According to Missagia et al., men place more importance on general healthiness whereas women tend to place more importance on foods that have beneficial effects on physical appearance ${ }^{(64)}$. However, the latter study was done in Brazil and $90 \%$ of the respondents were above 20 years old. In contrast, in the present study female adolescents in Indonesia seemed to place less emphasis on 'weight control', which can be inferred from the low variance and reliability of the subscale. To understand the differences between the results of our study and previous studies, differences in food perception between males and females should be investigated.

'Comfort' had no significant association with any of the independent variables. This may be because the items in the 'comfort' subscale all ask about individual physiological and psychological responses to food, whereas the independent variables in the present study were almost exclusively social and cultural. Future study could focus on the association of food-choice motives with physiological and psychological responses to food. Differences in scores on the comfort subscale should also be studied because those who have higher scores might make less healthy choices, particularly if many processed foods are readily available, as such foods are manufactured to increase the foods' sensory appeal ${ }^{(65)}$.

The present study had several limitations. First, the answers provided by the participants might not reflect what they actually think when making food-related decisions. The participants filled out the questionnaire while they were in their classroom together with their fellow students and the presence of their friends might have influenced their answers. Second, the participation rate was $61 \%$. In many cases this seemed to be due to the students forgetting to give the informed consent forms to their parents, or forgetting to bring the signed informed consent forms back to the school. In addition, some schools were more active in their participation in the study, such as by reminding students about the study, whereas other schools did not take such measures. However, there is no specific reason to expect that this situation had any systematic effect. That is, there was no reason to suspect that students forgetting the consent form or schools being unenthusiastic about participation was associated with the students' actual food-choice motives. Third, validation testing assessed only face validity (with the exception of the construct-validation testing of the FCQ).

Despite these limitations, the present study provides the first descriptive data on food-choice motives among junior-high-school students in Indonesia using the FCQ. It is the first study in which information about food-choice motives in Indonesia came from the FCQ reconstructed to fit that population. This is also the first study to examine other factors besides gender and age for their associations with food-choice motives, using multivariate analysis.

\section{Conclusions}

In conclusion, the factor structure of the FCQ was different from those reported in studies done in adults. Specifically, in the present study three motives were identified. The modified version of the FCQ can provide reliable measures of the food-choice motives of public juniorhigh-school students in Jakarta. Students from less affluent families placed more importance on food's convenience and price, and being more affluent did not guarantee that students would make healthier choices. Compared with female students, male students were more likely to choose healthy meals.

The FCQ could be used at baseline and again at follow-up should there be programmes to improve nutrition. At least in urban areas, it may be used to show exactly how strong the need is for economic-incentive interventions to improve nutrition. 


\section{Acknowledgements}

Acknowledgements: The authors would like to thank Professor Ratna Djuwita Hatma of the Department of Epidemiology and lecturers of the Department of Nutrition, Faculty of Public Health, Universitas Indonesia for their assistance during the data collection preparation. Financial support: This research received no specific grant from any funding agency in the public, commercial or not-for-profit sectors. Conflict of interest: None. Authorship: R.M. and K.N. designed the study. R.M. collected the data and drafted the paper. J.G. and A.S. contributed to the data management and data analysis. J.G., K.N. and M.J. contributed to final editing. All authors read and approved the final manuscript. Ethics of buman subject participation: This study was conducted according to the guidelines laid down in the Declaration of Helsinki and all procedures involving human subjects were approved by the Research Ethics Committee of the Graduate School of Medicine at the University of Tokyo in Japan (serial number: 10613) and the Research Ethics Committee of the Faculty of Public Health, University of Indonesia in Indonesia (reference: 99/ H2.F10/PPM.00/2014). Written informed consent was obtained from all subjects.

\section{References}

1. Popkin BM, Adair LS \& Ng SW (2012) Global nutrition transition and the pandemic of obesity in developing countries. Nutr Rev 70, 3-21.

2. Popkin BM (2002) The shift in stages of the nutrition transition in the developing world differs from past experiences! Public Health Nutr 5, 205-214.

3. Ahmed F, Zareen M, Khan MR et al. (1998) Dietary pattern, nutrient intake and growth of adolescent school girls in urban Bangladesh. Public Health Nutr 1, 83-92.

4. Dapi N, Janlert U, Nouedoui C et al. (2005) Adolescents' food habits and nutritional status in urban and rural areas in Cameroon, Africa. Scand J Nutr 49, 151-158.

5. Adair LS \& Popkin BM (2005) Are child eating patterns being transformed globally? Obes Res 13, 1281-1299.

6. Lytle LA, Seifert S, Greenstein J et al. (2000) How do children's eating patterns and food choices change over time? Results from a cohort study. Am J Health Promot 14, 222-228.

7. Julia M, van Weissenbruch MM, Prawirohartono EP et al. (2008) Tracking for underweight, overweight and obesity from childhood to adolescence: a 5-year follow-up study in urban Indonesian children. Horm Res 69, 301-306.

8. Soerachman R (2007) Indonesia Global School-Based Student Health Survey (GSHS) 2007. A Collaboration Project of Indonesia Ministry of Health, Indonesia Ministry of Education, the World Health Organization and the US Centers for Disease Control and Prevention. http://www.who.int/ chp/gshs/GSHS_Country_Report_Indonesia_2007.pdf (accessed December 2014).

9. Must A \& Strauss RS (1999) Risks and consequences of childhood and adolescent obesity. Int J Obes Relat Metab Disord 23, Suppl. 2, S2-S11.

10. Whitaker RC, Wright JA, Pepe MS et al. (1997) Predicting obesity in young adulthood from childhood and parental obesity. $N$ Engl J Med 337, 869-873.
11. Starc G \& Strel J (2011) Tracking excess weight and obesity from childhood to young adulthood: a 12 -year prospective cohort study in Slovenia. Public Health Nutr 14, 49-55.

12. Venn AJ, Thomson RJ, Schmidt MD et al. (2007) Overweight and obesity from childhood to adulthood: a follow-up of participants in the 1985 Australian Schools Health and Fitness Survey. Med J Aust 186, 458-460.

13. Biro FM \& Wien M (2010) Childhood obesity and adult morbidities. Am J Clin Nutr 91, issue 5, 1499S-1505S.

14. Tirosh A, Shai I, Afek A et al. (2011) Adolescent BMI trajectory and risk of diabetes versus coronary disease. N Engl J Med 364, 1315-1325.

15. Daniels SR, Pratt CA \& Hayman LL (2011) Reduction of risk for cardiovascular disease in children and adolescents. Circulation 124, 1673-1686.

16. Birch LL (1987) Children's food preferences: developmental patterns and environmental influences. Ann Child Dev $\mathbf{4}$, 171-208.

17. Fitzgerald A, Heary C, Nixon E et al. (2010) Factors influencing the food choices of Irish children and adolescents: a qualitative investigation. Health Promot Int 25, 289-298.

18. Truswell AS \& Darnton Hill I (1981) Food habits of adolescents. Nutr Rev 39, 73-88.

19. Croll JK, Neumark-Sztainer D \& Story M (2001) Healthy eating: what does it mean to adolescents? J Nutr Educ 33, 193-198.

20. Neumark-Sztainer D, Story M, Perry C et al. (1999) Factors influencing food choices of adolescents: findings from focus-group discussions with adolescents. J Am Diet Assoc 99, 929-937.

21. Contento IR, Williams SS, Michela JL et al. (2006) Understanding the food choice process of adolescents in the context of family and friends. J Adolesc Health 38, 575-582.

22. Stevenson C, Doherty G, Barnett J et al. (2007) Adolescents' views of food and eating: identifying barriers to healthy eating. $J$ Adolesc 30, 417-434.

23. Lindeman M \& Väänänen M (2000) Measurement of ethical food choice motives. Appetite 34, 55-59.

24. Share M \& Stewart-Knox B (2012) Determinants of food choice in Irish adolescents. Food Qual Prefer 25, 57-62.

25. Sun YH (2008) Health concern, food choice motives, and attitudes toward healthy eating: the mediating role of food choice motives. Appetite 51, 42-49.

26. Headrick LB, Rowe CC, Kendall AR et al. (2013) Adults in all body mass index categories underestimate daily energy requirements. J Nutr Educ Behav 45, 460-465.

27. Lien N, Jacobs DR \& Klepp KI (2002) Exploring predictors of eating behaviour among adolescents by gender and socio-economic status. Public Health Nutr 5, 671-681.

28. Shi Z, Lien N, Kumar BN et al. (2005) Socio-demographic differences in food habits and preferences of school adolescents in Jiangsu Province, China. Eur J Clin Nutr 59, 1439-1448.

29. Thang NM \& Popkin BM (2004) Patterns of food consumption in Vietnam: effects on socioeconomic groups during an era of economic growth. Eur J Clin Nutr 58, $145-153$.

30. Hanson MD \& Chen E (2007) Socioeconomic status and health behaviors in adolescence: a review of the literature. J Behav Med 30, 263-285.

31. Darmon N \& Drewnowski A (2008) Does social class predict diet quality? Am J Clin Nutr 87, 1107-1117.

32. Gillman MW, Rifas-Shiman SL, Frazier AL et al. (2000) Family dinner and diet quality among older children and adolescents. Arch Fam Med 9, 235-240.

33. Fink SK, Racine EF, Mueffelmann RE et al. (2014) Family meals and diet quality among children and adolescents in North Carolina. J Nutr Educ Behav 46, 418-422. 
34. Steptoe A, Pollard TM \& Wardle J (1995) Development of a measure of the motives underlying the selection of food: the food choice questionnaire. Appetite 25, 267-284.

35. Pollard TM, Steptoe A \& Wardle J (1998) Motives underlying healthy eating: using the Food Choice Questionnaire to explain variation in dietary intake. J Biosoc Sci 30, 165-179.

36. Schnohr CW, Kreiner S, Due E et al. (2008) Differential item functioning of a family affluence scale: validation study on data from HBSC 2001/02. Soc Indic Res 89, 79-95.

37. Turconi G, Celsa M, Rezzani C et al. (2003) Reliability of a dietary questionnaire on food habits, eating behaviour and nutritional knowledge of adolescents. Eur J Clin Nutr 57, 753-763.

38. Nunnally JC, Bernstein IH \& Berge JM (1967) Psychometric Theory. New York: McGraw-Hill.

39. Currie C, Molcho M, Boyce W et al. (2008) Researching health inequalities in adolescents: the development of the Health Behaviour in School-Aged Children (HBSC) family affluence scale. Soc Sci Med 66, 1429-1436.

40. Jáuregui-Lobera I \& Bolaños Ríos P (2011) What motivates the consumer's food choice? Nutr Hosp 26, 1313-1321.

41. Rouby C, Schaal B, Dubois D et al. (2002) Olfaction, Taste, and Cognition. Cambridge: Cambridge University Press.

42. Shepherd GM (2006) Smell images and the flavour system in the human brain. Nature 444, 316-321.

43. Rozin P (1982) 'Taste-smell confusions' and the duality of the olfactory sense. Percept Psychophys 31, 397-401.

44. Stevenson RJ, Oaten MJ \& Mahmut MK (2011) The role of taste and oral somatosensation in olfactory localization. QJ Exp Psychol 64, 224-240.

45. Blackwell L (1995) Visual cues and their effects on odour assessment. Nutr Food Sci 95, 24-28.

46. Stevenson RJ \& Oaten M (2008) The effect of appropriate and inappropriate stimulus color on odor discrimination. Percept Psychophys 70, 640-646.

47. Sakai N, Imada S, Saito S et al. (2005) The effect of visual images on perception of odors. Chem Senses 30, Suppl. 1 , i244-i245.

48. Kildegaard H, Olsen A, Gabrielsen G et al. (2011) A method to measure the effect of food appearance factors on children's visual preferences. Food Qual Prefer 22, 763-771.

49. French SA (2003) Pricing effects on food choices. J Nutr 133, issue 3, 841S-843S.

50. Glanz K, Basil M, Maibach E et al. (1998) Why Americans eat what they do: taste, nutrition, cost, convenience, and weight control concerns as influences on food consumption. J Am Diet Assoc 98, 1118-1126.

51. Darmon N \& Drewnowski A (2015) Contribution of food prices and diet cost to socioeconomic disparities in diet quality and health: a systematic review and analysis. Nutr Rev 73, 643-660.
52. Burns C, Cook K \& Mavoa H (2013) Role of expendable income and price in food choice by low income families. Appetite 71, 209-217.

53. DiSantis KI, Grier SA, Odoms-Young A et al. (2013) What 'price' means when buying food: insights from a multisite qualitative study with Black Americans. Am J Public Health 103, 516-522.

54. Schröder H, Marrugat J \& Covas MI (2006) High monetary costs of dietary patterns associated with lower body mass index: a population-based study. Int J Obes (Lond) 30, 1574-1579.

55. Maillot M, Darmon N, Vieux F et al. (2007) Low energy density and high nutritional quality are each associated with higher diet costs in French adults. Am J Clin Nutr 86, 690-696.

56. Morris MA, Hulme C, Clarke GP et al. (2014) What is the cost of a healthy diet? Using diet data from the UK Women's Cohort Study. J Epidemiol Community Health $\mathbf{6 8}$, 1043-1049.

57. Rao M, Afshin A, Singh G et al. (2013) Do healthier foods and diet patterns cost more than less healthy options? A systematic review and meta-analysis. BMJ Open 3, e004277.

58. Jones-Smith JC, Gordon-Larsen P, Siddiqi A et al. (2012) Is the burden of overweight shifting to the poor across the globe? Time trends among women in 39 low- and middle-income countries (1991-2008). Int J Obes (Lond) 36, $1114-1120$

59. Dinsa GD, Goryakin Y, Fumagalli E et al. (2012) Obesity and socioeconomic status in developing countries: a systematic review. Obes Rev 13, 1067-1079.

60. Neuman M, Kawachi I, Gortmaker S et al. (2013) Urban-rural differences in BMI in low- and middle-income countries: the role of socioeconomic status. Am J Clin Nutr 97, 428-436.

61. Vereecken CA, Inchley J, Subramanian SV et al. (2005) The relative influence of individual and contextual socio-economic status on consumption of fruit and soft drinks among adolescents in Europe. Eur J Public Health 15, 224-232.

62. Piggford T, Raciti M, Harker D et al. (2008) Young adults' food motives: an Australian social marketing perspective. Young Consum 9, 17-28.

63. Honkanen P \& Frewer L (2009) Russian consumers' motives for food choice. Appetite 52, 363-371.

64. Missagia SV, de Oliveira SR \& de Rezende DC (2012) Food choice motives and healthy eating: assessing gender differences. Presented at XXXVI Encontro da ANPAD, Rio de Janeiro, Brazil, 22-26 September 2012. http://www.anpad.org.br/admin/pdf/ 2012_MKT922.pdf (accessed December 2014).

65. Moss M (2013) Salt, Sugar, Fat: How the Food Giants Hooked Us. New York: Random House. 